Proceedings

\title{
COWORKING SPACES: THREAT OR OPPORTUNITY TO FACE CRISIS SITUATIONS
}

\author{
Maria del Mar Alonso-Almeida ${ }^{1, *}$, María Escat ${ }^{1}$ and Adriana Perez-Encinas ${ }^{1}$ \\ 1 Universidad Autónoma de Madrid, Faculty of Economics and Business Administration, Business Organiza- \\ tion Department ; maria.escat@uam.es; adriana.perez.encinas@uam.es \\ * Correspondence: mar.alonso@uam.es
}

Publisher's Note: MDPI stays neutral with regard to jurisdictional claims in published maps and institutional affiliations.

\section{(c) (i)}

Copyright: $\odot 2021$ by the authors. Submitted for possible open access publication under the terms and conditions of the Creative Commons Attribution (CC BY) license (http://creativecommons.org/licenses/by/4.0/).

\begin{abstract}
A crisis situation like COVID19 pandemic placed many workers at home and changed the mind of how business activities can be carried out. This paper analyses if coworking spaces help to work safe and overcome the problems derived from working at home. In-depth reviews of coworking websites were done and interviews with key players and users are under process. Website analysis classified a series of measures in three categories: sanitary, working together with social distancing and new products and services. Nevertheless, a deeper analysis on the positive and negative impact on coworking spaces under this new scenario is needed.
\end{abstract}

Keywords: coworking; occupational health; shared spaces; crisis times

\section{Introduction}

The working environment before COVID19 pandemic was influenced by the concepts of flexibility and sharing resources. Coworking is one of this type of new working styles by offering flexibility, a space for sharing resources and a community. A place where, individual workers such as entrepreneurs, freelancers and microbusinesses did not feel alone and could find support. Urban workspaces appeared in the wake of the Great Recession of 2007-2009. The financial crisis left empty commercial offices in U.S. cities due to downsizing, bankruptcy and foreclosure, increasing the number of workers who needed a more flexible workspace [1,2]. Subsequently, the emphasis shifted to the practice of new business activities with the construction of the "new economy" [3,4].

In addition to that, there is a growing tendency to collaborate towards the consumption of goods and services over the Internet [5]. This virtual space allows the establishment of business models that do not require the purchase of expensive and technically complex goods or services thanks to the concept of shared use [6]. In fact, with the current pandemic several companies changed their onsite business activities to work from home to maintain social distancing and avoid contagions, in other words, they continue their business in a safer environment.

Nevertheless, worldwide reports [7] show the difficulties to work at home and achieve a work-family and personal life balance. In addition, lack of social interaction and sedentary work patterns have also resulted in physical health-related problems, including an increasement of stress levels. Thus, the role of coworking spaces is under analysis. It could be considered a savior to face the new normal and contribute to a safer occupational environment. In this research, an in-depth analysis of the role of those working places to face crisis situations will be done based on the revision of websites, measurements taken by working places and perceptions of workers.

\section{Methods}

In order to understand how coworking spaces can help to work safe and overcome the problems derived from working at home, two different actions are being developed: 
firstly, in-depth websites review of Madrid coworking spaces. Secondly, interviews with key players of the industry and coworking spaces users are under process. Some of the main preliminary results of the web analysis are outlined below.

\section{Results}

An analysis of 12 websites of main coworking companies (more than 25 coworking spaces in Madrid) was carried out with a special emphasis in post lockdown measures.

After reviewing the websites, the following measures were identified:

- $\quad$ A schedule without limits or restrictions 24/7 hours per day, seven days per week.

- $\quad$ Advanced air filtration, virus and pollutant free space.

- Flexible time (morning, evening, night).

- $\quad$ Separated spaces (just for one person).

- Increase of new services.

- COVID19 protocol.

- Increased cleaning.

- Modification of shared spaces for teams can practice healthy social distancing in the workplace.

- $\quad$ Signage and directions in different languages as friendly reminders about social distancing and cleanliness.

- $\quad$ Reinforce standards of cleanliness with more frequent and intense cleaning

- Contactless mail and package delivery.

- Virtual spaces for companies legal obligations.

- Protection screens.

- $\quad$ Flexible price and time (since 5 euros per hour).

- Incensement of private offices.

- Digital transformation.

Thus, the measures can be classified in three different categories: 1) sanitary measurements, 2) working together but with social distancing measurements and 3) new products and services to face the new normal. The measurements are shown in table 1.

Table 1. Classification of post lockdown coworking spaces measures.

\begin{tabular}{ccc}
\hline Sanitary & $\begin{array}{c}\text { Working Together with social } \\
\text { distance }\end{array}$ & New products and Services \\
\hline Air filtration & Private offices & Data \\
COVID19 protocol & Redesign of Working Spaces & Flexible time operation \\
More cleaning & Virtual obligations \\
Signage anti-COVID19 & Contactless mail and package & delivery \\
& Protection screens & Flexible rates \\
& & More private offices \\
& & Digital transformation \\
\hline
\end{tabular}

Source: Own elaboration.

All of them contribute to reduce stress and maintain the relationship with others in a safe way. Specially, new products and services can help to conciliate when the whole family is working at home. Flexibility and an extended schedule are a step to make easiest the return to work- The creation of new products is a must to facilitate the possibility to have a private office where work without interruptions and with possibility of physical meetings with social distance.

\section{Conclusions}


Some conclusions can be emphasized as follows: coworking companies and spaces are growing worldwide and in Spain in number of companies and coworking positions. Spain ranks the $4^{\text {th }}$ worldwide, only behind United States, India and United Kingdom [8]. Those coworking spaces have adapted their spaces and operations to the new situation in order to provide trust to their coworkers and involving the employees in the solution for building a common sense of purpose.

The growing of coworking operators and spaces is changing the way people go to the office in Madrid. As the results shown, the post lockdown coworking spaces measures includes three categories (for becoming an opportunity to face crisis situations): sanitary, working together with social distance and new products and services. For instance, working together with social distance includes the redesign of working spaces considering the appropriate square footage per employee and adjusting desks to ensure a safe distance between each employee. "De-densifying" office space will require a new design of common areas and how people interact around the office. This might lead to improved ventilation, larger conference rooms, new kitchen protocol, one-way pathways, and reduced capacity in elevators. Enhanced cleaning protocols and the ubiquitous availability of hand sanitizer and disinfecting supplies will be essential [9].

Besides, there is a trend for companies to delay the hire or buy to a whole office, being the main reason avoiding debts and costs associated to ownership. Flex spaces can prove to be a problem solver as outsourcing office spaces to flexible workspace operators could substantially ease the commitments associated with maintaining a permanent staff whilst also ensuring that social distancing, sanitation and safe hygiene within premises is strictly adhered to [10]. However, it has not found any specific measurement to encourage women to use coworking spaces beyond the aforementioned measurement that they are not gender neutral.

The digital transformation will be one of the main steps in this new way for the coworking spaces. Need new digital strategies for new digital business models. Now, offices have become less important and work from home has suddenly become necessary. This emergency need for work from home is driving the digital transformation of the workforce and the evolution of the work environment at an unprecedented speed of telecommuting has become a vital business change since the outbreak of the virus. [11]

Finally, these insights also show that a deeper analysis is needed to identify coworking spaces positive and negative impacts regarding city spaces like urban transformation [12], citizens, and traditional working spaces among others.

We also consider that coworking spaces need to be resilience, accentuating the positive and strengthen communal bonds to restore confidence for bouncing back in this postpandemic world [13].

Author Contributions: M.M.A.A. has contributed, in all aspects to the paper reported. Specifically, conceptualization, methodology, data curation, formal analysis, investigation, supervision, and funding acquisition. M.E. and A.P.E, have contributed to investigation, writing-original draft preparation and writing - review and editing. All authors have read and agreed to the published version of the manuscript

Funding: This research was funded by the Ministry of Science and Innovation of Spain within its National Program for Research Aimed at the Challenges of Society. (Grant ECO2016-79659-R (Ecoinnovation and Circular Economy in the service sector)).

Conflicts of Interest: The authors declare no conflict of interest The funders had no role in the design of the study; in the collection, analyses, or interpretation of data; in the writing of the manuscript, or in the decision to publish the results.

\section{References}

1. Yu, Hui-Yong. Office vacancy rate in U.S. climbs to 17-year high, Reis says. Bloomberg, 2010, 6 July.

2. Kallenberg, A. L., \& von Wachter, T. M. The U.S. labor market during and after the great recession: Continuities and transformations. Journal of the Social Sciences, 2017, 3, 1- 19. 
3. Thrift, N. (2001) It's the Romance, Not the Finance, That Makes the Business Worth Pursuing: Disclosing a New Market Culture. Economy and Society, 2001, 30(4), 412-432.

4. Neff, G. Venture Labor: Work and the Burden of Risk in Innovative Industries, MIT Press Cambridge, United States, 2012.

5. Belk, R.You are what you can access: Sharing and collaborative consumption online. Journal of Business Research, 2014, 67(8), 1595-1600.

6. Orel, M., \& Alonso-Almeida, M.M. The ambience of collaboration in coworking environments. Journal of Corporate Real Estate, 2019, 21(4), 273-289.

7. Singh, A. Work from home to work from anywhere: The future of co-working spaces. 2020. Available at https://www.orfonline.org/expert-speak/work-home-anywhere-future-coworking-spaces/. Revised, December 8, 2020.

8. Fernandez-Cañete, M. Pronóstico del Coworking 2020 / 2021. 2020. Available at: https://coworkinglafabrica.es/pronostico-delcoworking-2020-2021/. Revised, December 30, 2020.

9. WeWork. Reimaging work in the era of COVID-19. WeWork. 2020. Available at https://www.wework.com/ideas/growth-innovation/reimagining-work-in-the-era-of-covid-19

10. Gusain, Arnab Singh, "Work from home to work from anywhere: The future of coworking spaces". Digital frontiers, October 27 $7_{\text {th }}$ 2020. Available at https://www.orfonline.org/expert-speak/work-home-anywhere-future-coworking-spaces/\#_edn23

11. Savic, Dobrica. "Impact of Covid-19 on digital transformation of the workforce. The impacts of digital transformation", 2020. EFEAAcademy. Available at http://acikerisim.deu.edu.tr:8080/xmlui/bitstream/handle/20.500.12397/13923/THE-IMPACTS-OFDIGITAL-TRANSFORMATION.pdf?sequence=1\&isAllowed=y\#page=36

12. Karan Virwani, "Flexible Workspaces: A Smart Solution to Build Smart Cities", Times of India Blog, Available at https://timesofindia.indiatimes.com/blogs/voices/flexible-workspaces-a-smart-solution-to-build-smart-cities/ August 04, 2020.

13. McKinsey \& Company. The path to the next normal. Leading with resolve through the coronavirus pandemic. 2020. Available at https://www.mckinsey.com/ /media/McKinsey/Featured\%20Insights/Navigating\%20the\%20coronavirus\%20crisis\%20collected \%20works/Path-to-the-next-normal-collection.pdf 